\title{
Report from the Executive Committee Meeting in Portoroz, 24-26 November 2017
}

\section{Richard Elwes, EMS Publicity Officer}

Last Autumn, the EMS's Executive Committee (EC) plus guests gathered in the Grand Hotel Bernardin in Portoroz on the stunning Slovenian Coast, on the kind invitation of the Society of Mathematicians, Physicists, \& Astronomers of Slovenia (DMFA) and the University of Primorska. The choice of venue was significant: in July 2020 the same site will host the 8th European Congress of Mathematics (8ECM). The congress was therefore at the forefront the committee's mind throughout the meeting; in particular, it offered those who had not already done so the opportunity to explore the area and facilities, under the guidance of the congress's local organisers.

On Friday afternoon, the committee was welcomed by Boštjan Kuzman, President of the DMFA's National Committee for Mathematics, who told us about his society's history and activities, as well as some general history of Slovene mathematics. The DMFA was founded in 1949 (when Slovenia was part of Socialist Federal Republic of Yugoslavia). Its first honorary member was Josip Plemelj (1873-1967), the First Rector of University of Ljubljana, famous for his solution to the Riemann-Hilbert problem concerning the existence of a differential equation with a given monodromy group. In 1992, after the break-up of Yugoslavia, the DMFA became a member society of the EMS. Today, the DMFA represents Slovenia in international settings, promotes research, organizes national and international mathematics competitions (including the 2006 International Mathematical Olympiad), publishes the journal Ars Mathematica Contemporanea alongside other journals, textbooks, and problem compendia, organises conferences for researchers, seminars for teachers, and assorted mathematical outreach events. Tomaž Pisanski then introduced some other facets of Slovene mathematical life, including the new Slovenian Discrete and Applied Mathematics Society (SDAMS), which was established in 2017 along with its journal The Art of Discrete and Applied Mathematics whose first edition was published in 2017.

\section{Officers' Reports and Membership}

The meeting opened with some words of welcome from the chair, EMS President Pavel Exner, who related his activities since the Spring meeting (many featuring in later items on the agenda). He closed with some reflections on the political situation around the world, noting that the EMS has a duty to raise its voice when mathematics is under threat, and the unique organizational structure of the EMS makes our voice strong. At the same time, the EMS is not principally a political organization, and to maximise our impact, we must be selective in deciding when to speak out.

The EMS Treasurer Mats Gyllenberg presented his report on the society's 2017 income and expenditure. The financial situation is healthy; however less money 
was spent on scientific projects than intended, something to bear in mind when allocating future funds. The EMS Secretary Sjoerd Verduyn Lunel then reported on preparations for the next EMS Council meeting (23-24 June 2018 in Prague).

The committee was delighted to approve an application for Institutional Membership from the Mathematical Institute, University of Oxford. Contrastingly, it regretted a notification of withdrawal from the French Statistical Society. Several other member societies remain severely in arrears on their fees, and at the next Council meeting it may sadly be necessary to propose that certain societies have their EMS membership terminated. The committee was pleased to approve a list of 155 new individual members.

\section{Scientific Meetings}

The committee heard an encouraging presentation from Klavdija Kutnar, deputy chair of the local organising committee of 8ECM, on plans for the 2020 congress. The President thanked her and chair Tomaž Pisanski for all the work their committee has already done, and wished them continuing success as the congress draws nearer. The EC then began the important discussion of the leadership and personnel of the congress's Scientific and Prize Committees, based on candidates proposed by member societies. The society is of course seeking top mathematicians for these roles, but also individuals with broad mathematical interests, who as part of their duties will attend the ECM in person. Good progress was made, and the discussion will continue at the EC's next meeting in Spring 2018.

The committee then discussed applications for support for scientific events in 2018, based on evaluations from the Meetings committee. The EMS distinguished speakers for 2018 will be Benoit Perthame at the Joint EMS-FMS-ESMTB Mathematical Weekend in Joensuu, Finland (4-5 January 2018) and Andre Neves at the at the 7th Iberoamerican Congress on Geometry in Valladolid, Spain (22-26 January 2018), which will also be supported as an EMS Special Activity. The EC agreed to support the following eight Summer Schools:

- Advanced Techniques in Mathematical Modelling of Tumour Growth, Centre de Recerca Matemàtica (CRM), Barcelona, 3-6 April 2018

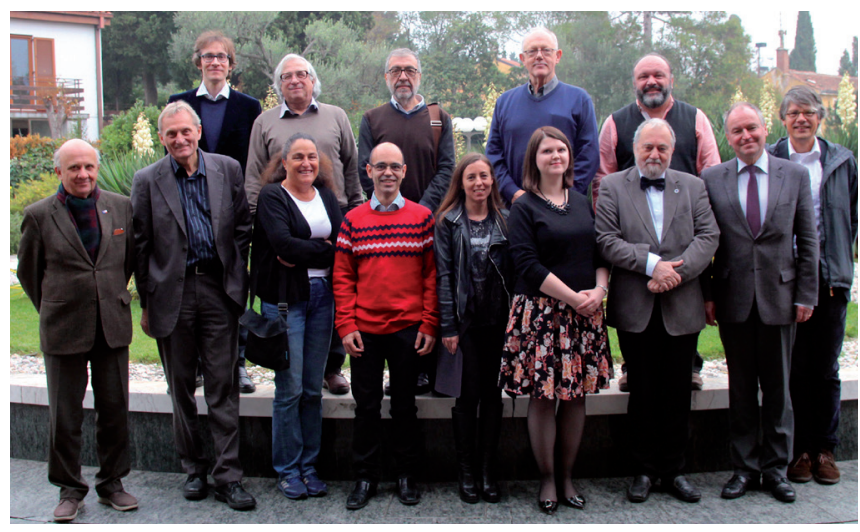

- New Results in Combinatorial \& Discrete Geometry, CRM, Barcelona, Spain, 7-11 May 2018

- EMS-EWM Summer School "Nonlocal interactions in Partial Differential Equations and Geometry", Institut Mittag Leffler, Stockholm, 21-25 May 2018

- EMS-IAMP summer school in mathematical physics: Universality in probability theory and statistical mechanics, Ischia, Italy, 11-15 June 2018

- Géométrie Algébrique en Liberté XXVI, Strasbourg, France, 18-22 June 2018

- 16th School on Interactions between Dynamical Systems and Partial Differential Equations, CRM, Barcelona, 25-29 June 2018

- 4th Barcelona Summer School on Stochastic Analysis, CRM, Barcelona, Spain, 9-13 July 2018

"Building Bridges", the 4th EU/US Summer School on Automorphic Forms and Related Topics, Alfréd Rényi Institute, Budapest, 9-14 July 2018

- Helsinki Summer School on Mathematical Ecology and Evolution, Turku, Finland, 19-26 August 2018.

The committee additionally agreed to support the 12th International Vilnius Conference on Probability Theory and Mathematical Statistics, Lithuania 2-6 July 2018, as well as the Emil Artin International Conference, Yerevan, Armenia, 27 May-2 June 2018. The President recalled that the EMS-Bernoulli Society Joint Lecture 2018 will be given at the European Conference on Mathematical and Theoretical Biology in Lisbon, 23-27 July 2018, by Samuel Kou.

\section{Officers, Standing Committees, and Projects}

The President reminded the committee that his term and that of Vice-President Volker Mehrmann, along with those of the Treasurer and Secretary, will end at the end of 2018. The next Council meeting in June 2018 will elect a new President and Vice-President; while the current Treasurer and Secretary declared that they would be available for re-election at the Council's pleasure.

Several of the EMS's standing committees also required replenishment of their membership and leadership, and the Executive Committee was pleased to make a number of appointments, including Stéphane Cordier and Koby Rubenstein as Chair and Vice-Chair respectively of the Applied Mathematics Committee, Leif Abrahamsson and Sophie Dabo as Chair and ViceChair of the Committee for Developing Countries, Jiří Rákosník and Dirk Werner as Chair and Vice-Chair of the Ethics Committee, Zdenek Strakos as Vice-Chair of the Meetings Committee, and Silvia Benvenutti as ViceChair of the Committee for Raising Public Awareness of Mathematics.

The outgoing President of the Applied Mathematics Committee, José Antonio Carrillo, in attendance as a guest, delivered a short report on his committee's activities including the exciting forthcoming Year of Mathematical Biology 2018. On behalf of the society, the President thanked him for his hard work over several years.

Mats Gyllenberg, liaison officer for the Committee for Developing Countries (CDC) delivered a short 
report on the first round of applications for the EMSSimons for Africa programme. The EC also discussed the problem of donations to the $\mathrm{CDC}$ decreasing over recent years. This is due largely to EMS members increasingly paying their dues through their local societies, rather than through the EMS webpage, where donations to the $\mathrm{CDC}$ are solicited.

The Executive Committee also discussed reports from the Committees on Education, Ethics, Meetings, European Solidarity, Publishing and Electronic Dissemination, Raising Public Awareness, and Women in Mathematics.

Discussions followed on other projects the EMS is involved with, including the online Encyclopedia of Mathematics (www.encyclopediaofmath.org), EUMATHS-IN (European Service Network of Mathematics for Industry and Innovation), the Global Digital Mathematics Library, Zentralblatt MATH (www.zbmath.org). The society's own newsletter was also discussed, with two new appointments made to the editorial team. The EMS's e-news, social media platforms, and other communications and publicity channels were also reviewed.

\section{Funding, Political, and Scientific Organisations}

The President gave an update of recent European Research Council (ERC) developments, with 2017 being its tenth anniversary year. The committee welcomed the news that former EMS President Jean-Pierre Bourguignon's term as President of the ERC has been extended.

The committee discussed recent developments regarding Horizon 2020 (and its successor framework), noting the importance of mathematicians registering as possible evaluators of Marie Curie proposals (a separate database from that of ERC evaluators).

Following the recent large increase in the membership fee for the Initiative for Science in Europe, after extensive discussions the committee agreed to terminate the EMS's membership of that body. The committee will investigate other pathways for political lobbying in Europe, given the importance of that task.

The President reported on the latest developments at the International Mathematical Union (IMU), in particular that Carlos Kenig has been proposed as the next IMU President for the period 2019-2022, and that Helge Holden intends to stay for a second term as Secretary. At the 2018 ICM in Rio de Janeiro, the general assembly will decide on the site for ICM 2022. The remaining two bids from Paris and Saint Petersburg, both being European, have each been endorsed by the EMS. Volker Mehrmann (member of the board of the International Council for Industrial and Applied Mathematics (ICIAM)) reported on the latest developments there. The President Elect is Ya-xiang Yuan, the next ICIAM conference will be in 2019 in Valencia (Spain), with ICIAM 2023 to be hosted in Tokyo. The EMS's relationship with various prize committees and research centres was also discussed, including proposing several nominations.

\section{Future Society Meetings and Closing Remarks}

The Executive Committee's next official meeting was set for 23-25 Match 2018 in Rome, before which it was agreed to meet for an informal retreat in Joensuu (Finland), 6-7 January 2018 to discuss the society's longterm strategic goals. The annual meeting of Presidents of EMS member societies will take place in Maynooth, Ireland, 14-15 April 2018 on the generous invitation of the Irish Mathematical Society. (In 2019 the corresponding meeting will take place at CIRM in Marseille, France.)

The meeting closed with the committee's warm thanks to the Society of Mathematicians, Physicists and Astronomers of Slovenia and to the University of Primorska, in particular to Klavdija Kutnar, Tomaž Pisanski, and Boštjan Kuzman, both for their impeccable organisation of this meeting and also for their ongoing efforts for the 2020 European Congress, to which the whole society is greatly looking forward. ed at the next Council. The committee was pleased to approve a list of 154 new individual members. 